
mutuales. Identificación. Concepto. Aplicación. Económicas CUC, 37(2), 177-194. DOI: http://dx.doi.org/10.17981/ econcuc.37.2.2016.09

\title{
Gobierno y gobernabilidad en las empresas mutuales. Identificación. Concepto. Aplicación ${ }^{1}$
}

DOI: http://dx.doi.org/10.17981/econcuc.37.2.2016.09

Pastor Emilio Pérez Villa²

\section{Resumen}

El objetivo central del artículo es el análisis de la gobernabilidad y el buen gobierno en las empresas mutuales de la ciudad de Medellín. Para cumplir esta finalidad, se desarrolló una investigación cualitativa de alcance descriptiva y método etnográfico; la técnica de recolección de información primaria fue la observación participante. Los resultados muestran que se debe establecer un sistema de gestión mediante el cual, los diferentes órganos de las mutuales cumplan cada uno su función con responsabilidad, compromiso, eficacia, eficiencia, ética y transparencia. Como conclusión, se observó que la práctica de los valores y principios, se convierte en la máxima expresión del Gobierno en las mutuales.

Palabras clave: gobierno regional; gobernabilidad; responsabilidad social; empresas mutuales; MedellínColombia.

Recibido: 18.5.2016 Devuelto para revisión: 12.7.2016 Aceptado: 9.8.2016

\begin{abstract}
1 Artículo científico derivado de la investigación "Gobierno y Gobernabilidad en las Empresas Mutuales. Identificación. Concepto. Aplicación”, financiada por el Comité Nacional para el Desarrollo de la Investigación CONADI UCC.

2 Magister en Ciencias Geológicas. Ingeniero Geológico. Instituto de Minas de Leningrado (URSS). Especialista en Alta Gerencia y Economía Solidaria. Universidad Cooperativa de Colombia. Profesor asociado de la Universidad Cooperativa de Colombia UCC, adscrito al grupo de investigación en Desarrollo Organizacional. pastor.perez@campusucc.edu.co
\end{abstract}

- The author; licensee Universidad de la Costa - CUC. 


\title{
Government and governance in mutual enterprises: identification, concept, application
}

\begin{abstract}
The aim of this article is to analyze government and good governance in the mutual companies in Medellin city. To achieve the objective, a qualitative research of descriptive scope and ethnographic method was developed; the technique of primary information collection was participant observation. The results indicated that a management system must be established whereby the different organs of the mutual fulfill each their function with responsibility, commitment, effectiveness, efficiency, ethics and transparency. In conclusion, was observed that the practice of values and principles becomes the maximum expression of the Mutual Government.
\end{abstract}

Keywords: regional government; governance; social responsibility; mutual companies; Medellín- Colombia.

\section{Introducción}

En los últimos 10 a 15 años, la literatura académica ha producido una larga lista de artículos analizando la relación que existe entre los diferentes aspectos que constituyen el gobierno de la corporación, tanto desde el punto de vista teórico como del empírico. Esta literatura ha analizado, además, la relación entre estos aspectos del gobierno corporativo y el desempeño de la empresa y de la economía (Lefort, 2003).

El concepto de gobierno corporativo (GC), es el conjunto de principios y normas que regulan el diseño, integración y funcionamiento de los órganos de gobierno de la empresa, como son los tres poderes dentro de una sociedad: los accionistas (asociados), directorio (junta directiva; consejo de ad- 
ministración) y alta administración (gerencia y asesores). La Organización para la Cooperación y el Desarrollo Económico (OCDE), emitió en mayo de 1999 sus Principios de Gobierno Corporativo en los que se encuentran las ideas básicas que dan forma al concepto que es utilizado por los países miembros y algunos otros en proceso de serlo.

La gobernabilidad se refiere a dos acepciones principales: la primera, que nace de los informes del Banco Mundial, la define como un estilo de gobierno caracterizado por un mayor grado de cooperación e interacción entre el Estado (empresa) y actores no estatales al interior de redes de decisiones mixtas públicas y privadas. La segunda se define como un conjunto de modalidades de coordinación de las acciones individuales, entendidas como fuentes primarias de construcción del orden social; es probable que se derive del campo de la economía de costos y transacciones. Por extensión, gobernabilidad es definida como cualquier forma de coordinación social (Colombo, 2003)

La responsabilidad social empresarial (RSE) renueva la concepción de la empresa, otorgando a ésta una dimensión amplia e integradora que va más allá de la mera cuestión económica en la que se incorpora perfectamente la triple faceta de la sosteni- bilidad: económica, social y medioambiental. El desarrollo sostenible se sitúa como fin a alcanzar por medio de la adecuada implementación de un modelo de empresa socialmente responsable, en el que los distintos grupos de interés (stakeholders) son el centro de atención esencial para la gestión.

Desde los años cincuenta, la significación de la ética en los negocios se ha venido desarrollando como una nueva cultura empresarial, al respecto Cortina señala que “(...) la RSE surge de la comprensión de la empresa como una institución socioeconómica que tiene una responsabilidad moral con la sociedad" (1994).

A través de la expresión de las ideas e identificación de los elementos conceptuales de la RSE, se propone una definición precisa del concepto y se establece una clara diferenciación con otros términos relacionados con la RSE frecuentemente utilizados de manera inapropiada, como por ejemplo: acción social, reputación corporativa, ética empresarial, marketing con causa social, sostenibilidad, entre otros (Reyno, 2006).

Hechos como la Conferencia de Estocolmo en 1972, el Informe Brundtland en 1987 o el protocolo de Kyoto en 1997; el nacimiento de grupos civiles como Am- 
nistía Internacional, WWF, Greenpeace o Transparencia Internacional; las iniciativas formales empresariales como AA1000, SA8000, las directrices de la OCDE o el mismo Pacto Mundial; así como el surgimiento de organizaciones como la Global Reporting Inititative o el Instituto Ethos, son todos, acontecimientos que han servido como bloques para levantar esta construcción social y medioambiental conocida como RSE. Además, así como las Normas ISO 9000 e ISO 14000 y las OHSAS 18000 han ayudado a las empresas en su gestión, hoy aparece la guía ISO 26000 sobre responsabilidad social para mejorar la gestión empresarial en torno a lo social. La RSE no es estática y seguirá cambiando y mejorando. Hoy se puede definir como: la relación que la empresa establece con todos sus públicos (stakeholders) a corto y a largo plazo.

Junto con la Federación de Mutuales de Antioquia (FEDEMUTUALES), se observó la falta de discusión sobre gobierno y gobernabilidad en las empresas mutuales, ya que este debate, aún no realizado, es necesario.

El modelo de gobierno es uno de los elementos diferenciadores de las empresas de economía social con relación a las empresas capitalistas tradicionales. Estas primeras son organizaciones gestionadas democráticamente por sus asociados, quienes participan activamente en la fijación de sus políticas y en la toma de decisiones, es decir, se basan en una democracia económica, en la autogestión y en el proceso de toma de decisiones; el principio de una persona, un voto, son elementos del modelo de gobierno de las empresas de economía social y, en particular, de las empresas mutuales. Esta característica señala la identidad empresarial. Este modelo de gobierno históricamente ha enfrentado y enfrenta dos interrogantes: ¿cómo conciliar su modelo democrático con las transformaciones generadas como consecuencia del crecimiento y desarrollo empresarial de las cooperativas? y ¿cómo seleccionar y dirigir a sus directivos?

Por lo anterior, es muy conveniente empezar a incorporar en los conversatorios estas expresiones y conceptos, ya que así se pueden precisar los diferentes problemas que tienen las empresas mutuales; además, también servirá para incorporar la gestión ética socialmente responsable en la mutual como elemento esencial de gestión.

\section{Metodología}

El método de investigación utilizado fue la etnografía, entendida como técnica cualitativa que se propone ayudar a interpretar 
el entorno a través del análisis de lo que dicen, hacen o piensan sus protagonistas; implica rigor teórico, técnico y metodológico con apertura y flexibilidad para el registro y el análisis.

Etimológicamente, el término etnografía significa la descripción (grafé) del estilo de vida de un grupo de personas habituadas a vivir juntas (ethnos). Por tanto, el ethnos, que en nuestro caso es la unidad de análisis, podría ser cualquier grupo humano que constituya una entidad cuyas relaciones estén reguladas por la costumbre o por ciertos derechos y obligaciones recíprocos. En la economía solidaria, las empresas mutuales son unidades sociales que pueden ser estudiadas etnográficamente.

El enfoque etnográfico se apoya en la convicción de que las tradiciones, roles, valores y normas del ambiente en que se vive se van internalizando poco a poco y generan regularidades que pueden explicar la conducta individual y de grupo en forma adecuada. En efecto, los miembros de una empresa mutual comparten una estructura lógica o de razonamiento que, por lo general, no es explícita pero que se manifiesta en diferentes aspectos de la organización.

Esta técnica de observación utilizada en las ciencias sociales se consideró que era la más adecuada, ya que el investigador logra compartir con los investigados su contexto, experiencia y vida cotidiana para conocer directamente toda la información que poseen los sujetos de estudio sobre su propia realidad.

El investigador mantuvo una permanencia relativamente prolongada en el seno de estas empresas mutuales: primero a través de un diplomado en la Universidad Cooperativa de Colombia, sede Medellín, sobre Mutualismo Empresarial con énfasis en Microfinanzas (donde se identificó el problema y se tomó la actitud básica de tipo exploratorio), durante meses y, posteriormente, con un seguimiento; luego se dio el Foro Regional Mutualista de Antioquia, con el tema de Gobierno y gobernabilidad en las empresas mutuales y la presencia de 410 asistentes del país e invitados de México, El Salvador, Argentina y Guatemala.

Utilizando la observación participante, se contempló a las asociaciones mutuales en lo relacionado con la gobernabilidad, con un papel activo de investigador, prestando atención a lo que ocurre y solicitando explicaciones e interpretaciones sobre las decisiones, acciones y comportamientos.

Durante el proceso de investigación se utilizó como técnica primaria para recoger la información, las anotaciones de campo 
tomadas in situ o después del evento observado, y después, se complementaron y corroboraron estas notas de campo con entrevistas estructuradas o no estructuradas (todo de acuerdo con las sugerencias de cada circunstancia) al conjunto de informantes, previa selección. Posteriormente, se realizó el proceso de socialización con el grupo investigado.

La información que se acumuló y las teorías emergentes se usaron para reorientar la recolección de nueva información; es decir, que se dio un proceso dialéctico, logrando un orden sistemático fiel a la realidad que emergió del proceso de investigación.

Este enfoque es en esencia holista y molar, es decir, amplio, y que permite ver, describir y comprender las realidades como formas totales estructuradas y complejas, como fenómenos interconectados que se integran y adquieren sentido por sus relaciones e influencia recíproca. En esta orientación metodológica no hay un diseño acabado dado con anterioridad. El diseño emerge en el transcurso de la investigación; es más, nunca finalizará, sino que estará en constante flujo a medida que la nueva información se acumula y avanza la comprensión de la realidad estudiada, la cual, en este caso, no es estática, única e invariable.

\section{Resultados}

El presente trabajo es un intento de contribuir a la discusión sobre el tema (¿problema?) de la gobernabilidad y el buen gobierno en las empresas de economía solidaria y, concretamente, en las empresas mutuales de la ciudad de Medellín, departamento de Antioquia, República de Colombia.

La razón por la que se planteó este proyecto se debe a que se identificó por parte de los líderes mutualistas, asistentes al diplomado, que éste es un tema coyuntural y de trascendencia desde lo social y económico. Se observó, también, que las empresas capitalistas compiten más eficientemente, mientras que las mutuales y otras empresas del sector de la economía social y solidaria trabajan de manera muy individualista y muy pocas poseen modelos de balance social, gobernabilidad, ética y liderazgo transparentes que les garanticen la credibilidad, no solamente ante sus asociados, sino también de la opinión pública en general. La gran mayoría, sin importar el tamaño, ha enfrentado dificultades, conflictos, pérdida de confianza y desestabilización por los problemas de gobierno.

De los estudios previos del mutualismo se deduce que estas organizaciones sur- 
gen con una tremenda escasez de factores productivos y, por ello, se apalancan principalmente en los de trabajo, la comunidad y la gestión (Suescún y Zabala, 2010). Generalmente, en la práctica, las decisiones se efectúan en la junta directiva y en la representación legal delegada.

Se encontró que cerca del $68 \%$ de la población objeto de esta investigación no presenta informes a la superintendencia de la economía solidaria (SES) y tampoco elaboran un balance social; no poseen código de ética y de buen gobierno. Los hallazgos son propios de todo el sector de la economía solidaria colombiana: pérdida de la naturaleza y, por ende, de la esencia; deficiencia en la estructura; un marco legal en discusión e inadecuado; mucha ausencia de procesos educativos y de integración. Lo anterior conlleva al reto de aplicar la gobernabilidad y el buen gobierno en estas empresas para tener más coherencia y cohesión y, por ende, mayor eficacia, manteniendo la eficiencia, la ventaja competitiva y la interdependencia.

\section{Discusión}

Para adentrarse en los conceptos de gobierno y gobernabilidad, se hace necesario hablar sobre los valores. Adela Cortina plantea: “(...) recopilar los valores éticos de una sociedad pluralista no es muy complicado, basta con recordar los tres de la Revolución Francesa (libertad, igualdad, solidaridad) y ampliar desde ellos el espectro..." (2002). En las empresas de economía solidaria se puede afirmar lo mismo. En estas empresas se retoman valores como la libertad, entendida como: independencia, participación, autonomía; libertad de expresión, de conciencia, de asociación, de reunión; una libertad que apareja responsabilidades. Así mismo, participación en la asamblea y en la toma de decisiones con autonomía, con criterio; igualdad, referente a dignidad, igualdad económica y de competencias; solidaridad; respeto como tolerancia; y diálogo como negociación y reconocimiento.

De esta forma, es necesario educar en los valores anteriores para incorporarlos en las creencias de la vida empresarial y del asociado. A la par con lo anterior, ellos se insertarán en las comunidades, educando al asociado y a ésta en torno al desarrollo.

Todo lo anterior se condensa con la implementación de una cultura de valores como herramienta de liderazgo que genere compromisos colectivos. En estas empresas, el líder debe conformar, desarrollar y garantizar el cumplimiento de valores compartidos. 


\section{VALOR}

"Así es como

ha de ser"

\section{OBJETIVO}

"Esto es lo que vamos a conseguir"

\section{REALIDAD}

"Esto es lo que

hemos conseguido"
El liderazgo es la "capacidad que tiene una persona o un grupo de personas de pensar y entender los problemas, presentar propuestas e ideas para lograr mejorar la situación, buscar soluciones, obtener resultados, dirigir, planificar, comunicar, tomar decisiones, escuchar y motivar a los otros" (González, 1995). Sobre todo lo anterior, una síntesis válida se incluye en el Cuadro 1.

La RSE se debe afianzar en el corazón de los lineamientos estratégicos y debe tener asiento dentro de la estructura organizacional. La RSE, como modelo de gestión, se incorpora sustancialmente en la misión, visión y valores de la empresa, así como en su estrategia y en su cultura organizacional (Guédez, 2008). En las empresas de economía solidaria se dan los triples impactos de la RSE propuestos por Víctor Guédez, en una perspectiva no sólo cuantitativa sino cualitativa (Cuadro 2).
Cuadro 1

Valores y principios: guía para la acción.

\begin{tabular}{|c|c|c|}
\hline $\begin{array}{l}\text { Valores de primer } \\
\text { orden } \\
\text { (fines en sí mismos) }\end{array}$ & $\begin{array}{l}\text { Valores de } \\
\text { segundo } \\
\text { orden }\end{array}$ & Principios \\
\hline Valores políticos: & Democracia & $\begin{array}{l}\text { Ingreso } \\
\text { voluntario y } \\
\text { abierto }\end{array}$ \\
\hline Libertad & Equidad & $\begin{array}{l}\text { Control } \\
\text { democrático }\end{array}$ \\
\hline Igualdad & $\begin{array}{l}\text { Autoayuda } \\
\text { Esfuerzo } \\
\text { propio }\end{array}$ & Participación \\
\hline Solidaridad & Confianza & $\begin{array}{l}\text { Autonomía } \\
\text { Independencia }\end{array}$ \\
\hline Valores Éticos: & & Cooperación \\
\hline Honestidad & & $\begin{array}{l}\text { Preocupación } \\
\text { por la } \\
\text { Comunidad }\end{array}$ \\
\hline
\end{tabular}

Apertura

Responsabilidad social

Cuidado de los otros

+ Educación, capacitación, información + sociedad civil establecida.

Fuente: adaptado por Pastor Emilio Pérez Villa de Johnston Birchall (2005). 
Cuadro 2

Impactos de la RSE en la empresa de economía solidaria.

\begin{tabular}{|c|c|c|c|}
\hline Impactos & $\begin{array}{c}\text { Financiero- } \\
\text { operacionales }\end{array}$ & Humano - sociales & Ambientales \\
\hline Tangibles & $\begin{array}{l}\text { Producto (portafolio de servicios) } \\
\text { Calidad (ISO } 9000 \text { basado en valores y } \\
\text { principios de la economía solidaria) } \\
\text { Valor añadido (todo lo relacionado con el } \\
\text { concepto económico "sin ánimo de lucro") }\end{array}$ & $\begin{array}{l}\text { Impacto social } \\
\text { Atracción y retención de } \\
\text { talentos } \\
\text { Dedicación laboral }\end{array}$ & $\begin{array}{l}\text { Reducción de } \\
\text { residuos } \\
\text { Control ambiental } \\
\text { Higiene }\end{array}$ \\
\hline Intangibles & $\begin{array}{l}\text { Confianza } \\
\text { Referencia } \\
\text { Reconocimiento } \\
\text { Identidad (doble carácter: económico - } \\
\text { social; empresa - asociación). }\end{array}$ & $\begin{array}{l}\text { Condiciones laborales } \\
\text { (sobre todo en las CTA) } \\
\text { Seguridad, bienestar. } \\
\text { Derechos humanos } \\
\text { (principios y valores) } \\
\text { Justicia distributiva } \\
\text { (repartición de excedentes) } \\
\text { Reputación }\end{array}$ & $\begin{array}{l}\text { Biodiversidad } \\
\text { Ambiente } \\
\text { estimulante } \\
\text { Imagen }\end{array}$ \\
\hline
\end{tabular}

Fuente: adaptado por Pastor Emilio Pérez Villa de Guédez (2008).

Las empresas de economía solidaria, desde sus inicios, vienen realizando un balance financiero y un balance social y, desde 1998 en Colombia (Ley 454 de 1998), se trabaja también el aspecto medioambiental; inclusive, algunas de estas empresas no sólo se han certificado en ISO 9000 (Pérez Villa y Múnera Vásquez, 2007), sino también en ISO 14000.

El centro de este ejercicio también hace parte estratégica de la misión, la visión, los valores y los principios; siendo los dos últimos, la esencia del sector y, por ende, de lo social. De esta manera, la RSE no representa la cereza sobre el postre; más bien, es parte de los ingredientes. Con el modelo de Marcelo Paladino, adecuado por Víctor Guédez, finalmente se entiende el por qué y para qué una RSE incorporada a la misión, visión, valores y principios de una cultura organizacional:

Cómo actuar: la operalización de la RSE debe estar incorporada a la dinámica de la organización (gestión: empresarial y social).

Sustentabilidad: la evaluación de la RSE debe permitir una re-orientación de la gestión. Prácticamente un ciclo PHVA al cual se le añaden los indicadores para la mejora continua. 
A mayor nivel de participación y democracia presente en las mutuales, y en cualquier institución, más sostenible a largo plazo será el trabajo de las mismas. La empresa mutual, desde sus propios orígenes, tiene un espíritu esencialmente democrático. La democracia es un proceso que cada día se renueva, es decir, las demandas democráticas cambian con la época. Alcanzar una sociedad más justa y solidaria, donde los niveles de bienestar sean asequibles para cada uno de los ciudadanos, es una finalidad de la democracia. La democracia no puede ser una palabra desprovista de contenido, sino que la misma debe ser un proceso dinámico y permanente que permee todas las actividades de nuestra vida social. Además, el mutualismo concibe al hombre holísticamente, no como receptor de beneficios materiales sino como persona, como ser humano. Cuando se habla de democracia en el movimiento mutualista, ésta se observa en el ámbito interno, por una parte, como un espacio donde se ejercitan los asociados en la práctica de la democracia participativa, y por otra, en el ámbito que se expresa de cara a la sociedad, como una propuesta de gestión económica, en la cual, a diferencia del modelo neoliberal, el ser humano es lo primero.

En el XXX Congreso Cooperativo de Bélgica se desarrolló la idea de que el principio fundamental de la cooperación es la demo- cracia y no el retorno (Lambert, 1959). La participación y la democracia son conceptos relacionados: sin participación no hay democracia, o lo que es lo mismo, para que haya democracia es necesaria la participación. En la empresa mutual, el valor de la participación exige que el asociado comparta efectiva y realmente las decisiones y el control de la empresa; que participe activamente en los riesgos económicos, técnicos y financieros; que lo haga también en la formación y el incremento del capital, las reservas y los fondos sociales; y que participe con fidelidad en las actividades económicas y sociales, objeto de la empresa, así como en el beneficio de sus servicios, de los resultados y de los excedentes.

La participación determina el grado y la eficiencia del compromiso asociativo y refuerza la identidad empresario-asociado, desde el punto de vista de la responsabilidad y del beneficio. La participación, cuando es real y efectiva, constituye una fuerza de atracción social que mantiene la fidelidad del asociado y estimula el ingreso de nuevos. Cuando es simplemente literaria, produce el efecto contrario.

El concepto de democracia, en términos generales, puede expresarse a través de dos concepciones básicas: la concepción crítica, que desarrolla un concepto normativo con respecto a los valores al expresarlos como 
un concepto ideal-teleológico que persigue la autodeterminación de los seres humanos, y por otro lado, la concepción positivista, que entiende la democracia como procedimiento para la toma de decisiones (Pérez Villa, 2007).

De aquí arrancarían dos concepciones clave: una, de carácter sintético, que exige el principio del gobierno representativo y responsable sujeto a control parlamentario y al de las elecciones, y otro, de carácter comprensivo, que entiende la democracia como un sistema institucional que tiene la finalidad de tomar decisiones y donde los individuos adquieren el poder de decidir mediante un proceso de elección colectiva en un ámbito de competencia, con solidaridad, ayuda mutua, transparencia y eficiencia.

Un grado más elevado de legitimación del poder está dado por la participación de los dirigidos en la toma de decisiones. Esta participación implica un perfeccionamiento especial de la gestión. El grado superior de legitimación de la autoridad se establece en la autogestión. Aquí desaparece toda separación entre dirigentes y dirigidos porque los mismos que ejecutan las actividades, las deciden conforme a sus propios objetivos y respetando ciertas normas y procedimientos que ellos autónomamente han acordado. La participación puede definirse en su esencia como la cooperación de los dirigidos en el ejercicio de la dirección y gestión de una organización compleja; cooperación en la toma de decisiones, cooperación en el sistema de dirección y gestión.

La autogestión es más que eso, es el ejercicio pleno de la dirección y gestión efectuada de manera asociativa y solidaria por todos los integrantes de una organización operando como un solo sujeto social. La participación y la autogestión son expresión de la solidaridad a la vez que la crean y refuerzan. La participación y la autogestión configuran un sujeto colectivo, asociativo o comunitario (Razeto Migliaro, 1993).

En un estudio realizado por Anna Clemencia Vivas Cuarta (Unidad de Estudios Solidarios UNES, 2005) se plantea que los gerentes y dirigentes del sector solidario hacen que estas organizaciones sean reconocidas como la mejor alternativa para el desarrollo integral del ser humano, jalonando prácticas autogestionarias de sus asociados y aplicando los principios fundamentales de la economía solidaria, como la autogestión, entendida como el proceso de plantear propuestas de solución y sobrevivencia de todos y cada uno de los integrantes de la organización al propender por acabar con la concepción piramidal. La autogestión se convierte en el nuevo derecho de la persona "el derecho a la autonomía personal". 
Para prevenir la ocurrencia de daños y promover el cumplimiento de los compromisos y el logro de la competitividad se propone la correcta aplicación del gobierno corporativo (GC). La gobernabilidad remite a la gestión concreta de las mutuales, a cómo se lleva a cabo el plan estratégico, cómo se relacionan los asociados, cómo se cumplen las normas, cómo se comunican con la sociedad y cómo se integran. Siempre hay que crear, poner en marcha y dirigir empresas que desde su nacimiento generen confianza, presencia social, seguridad, transparencia y pertenencia.

El concepto del GC trata de estructurar adecuadamente las relaciones entre la junta directiva, el comité de vigilancia y los auditores de una empresa (triángulo interno), pero también con agentes externos, tales como los empleados o clientes de la corporación y, sobre todo, con sus accionistas (triángulo externo). Si estas estructuras son eficientes, aseguran la estabilidad de la empresa y dan resultado en la práctica, se puede hablar de un "buen gobierno" (Arzbach, 2004).

La separación entre propiedad y gestión, que si bien puede producir ventajas como la especialización de las funciones, lleva inherente el riesgo de conflictos de intereses (Comisión Olivencia, 1998). Es decir, la separación de propiedad y control, tal y como se presenta en la empresa moderna, tiene como principal problema evitar los posibles comportamientos oportunistas de los gestores que tienden a reducir el valor empresarial (Gedajlovic, 1998).

Conceptos como GC, buen gobierno, código de buen gobierno y RSE causan confusión y, en determinadas ocasiones, un uso inapropiado. La gobernabilidad y el gobierno corporativo están intrínsecamente unidos, son parte de la misma cosa, no podemos hablar de uno sin referirnos al otro.

Según Santonja, no existe una definición generalizada de lo que es el buen gobierno corporativo. El único componente o principio inherente en todo buen gobierno corporativo es la ética. La ética, según su etimología, es relativa al carácter por lo que deriva del latín ethos, "carácter, manera de ser"; por tanto, ésta se manifiesta en las obras y actividades del hombre (Santonja, 2005). Para Sen, los planteamientos económicos, según los cuales los individuos se comportan de manera racional intentando maximizar su propio interés, resultan de una errónea interpretación de las teorías de Adam Smith (Sen, 2001). No sólo la ética tiene relación con la economía, sino que ésta, a su vez, se ha enriquecido considerablemente con algunos de los métodos utilizados por la economía (Sen, 2001). 
Estudiosos del cambio en las organizaciones consideran que las únicas empresas que sobrevivirán con éxito el proceso de globalización y de cambios deben rescatar lo ético en la empresa. Bernardo Kliksberg afirma que "la globalización ha tenido lugar en un vacío ético, donde el éxito y los fracasos del mercado tendían a convertirse en el máximo estándar de conducta”. En la actualidad, la discusión sobre la ética es impulsada por la ciudadanía, quienes demandan una respuesta efectiva como consumidores y como clientes de las empresas (Kliksberg, 2008).

Buen gobierno e identidad de empresa construye un lazo indisoluble. La identidad de una empresa sólo está asegurada por el buen obrar (ético) del buen gobierno, por lo que toda "acción mala o no ética", no coherente con el buen gobierno destruye la identidad, la esencia de la empresa (XV Congreso Nacional de Ética de la Economía y de las Organizaciones, 2007).

Charkham señala que el punto de partida para analizar los propósitos organizativos debe enmarcarse en el contexto del gobierno corporativo (el gobierno de la empresa o gobierno corporativo, o corporate governance en la terminología anglosajona) ya que, además de tener el poder de influir sobre los mismos, analiza los procesos de supervisión de las decisiones y acciones ejecutivas, así como los temas relacionados con la res- ponsabilidad y el marco legal de la organización (Charkham, 1994).

Son muchos los aspectos que conforman el gobierno corporativo y condicionan, de una $\mathrm{u}$ otra forma, el desempeño de la empresa. Entre los aspectos propios a la empresa se destacan: el sistema de toma de decisiones, la estructura de capital, los mecanismos de compensación a los ejecutivos y los sistemas de monitoreo. Entre los aspectos exógenos a la empresa son fundamentales: el sistema legal, el mercado por el control corporativo, el mercado por los servicios gerenciales y el grado de competencia en los mercados de bienes e insumos que enfrenta la empresa. Estas diferentes dimensiones del GC pueden afectar el desempeño y valor de la empresa.

Gobierno mutualista. El gobierno de la empresa mutual es un proceso, es decir, una actividad permanente, no una o varias decisiones aisladas; ese proceso es de supervisión y control, y no de gestión, lo que no excluye el ejercicio de acciones ejecutivas para desarrollar apropiadamente esas funciones de supervisión y control. Aquí, lo que se supervisa y controla es la dirección o gestión de la empresa en un sentido más amplio; la supervisión y el control del equipo directivo no son ejercidos sólo por órganos internos como la junta directiva, sino también por mecanismos externos. La finalidad 
del proceso es alinear los intereses de gestores y asociados en la dirección marcada por estos últimos, que, en una economía de mercado, no puede ser otra que la maximización del valor de la empresa, teniendo en cuenta que existen otros intereses como los de los empleados, acreedores, proveedores o la comunidad.

Gobernabilidad mutualista. Gobernabilidad o "buen gobierno" en la empresa mutual significa, entre otras cosas, la garantía de que la provisión de servicios se realiza sobre la base de principios de equidad, honestidad y transparencia.

Se propone como definición de gobernabilidad, para la empresa mutual, el ejercicio de cualquier autoridad económica y administrativa en la gestión de los asuntos de la asociación a todos los niveles, entendiendo que ésta comprende los mecanismos y procesos a través de los cuales los asociados, clientes y usuarios articulan sus intereses, ejercitan sus derechos legales, cumplen sus obligaciones y solucionan sus diferencias. Ésta se debe dar siempre en un ámbito social en el que se registren las demandas de los asociados, que son procesadas en menor o mayor medida por la junta directiva.

Viabilidad de la gobernabilidad mutualista. Para que la gobernabilidad sea viable debe cumplir con:
- Legitimidad: democracia, transparencia, rendición de cuentas y participación

- Eficiencia/Efectividad: llevar a la práctica exitosamente las medidas que han decidido ser implementadas.

- Eficacia: la eficacia pone énfasis en la capacidad del gobierno de formular las políticas y ocuparse de su función que le es propia. La eficacia y la eficiencia son valores propios de la gestión.

- Estabilidad: la capacidad del gobierno de adaptarse flexiblemente con respecto a los cambios y las exigencias del entorno y durar de esta manera en el tiempo.

- Ajustarse a la normatividad que regula el movimiento mutualista y el sector de la economía solidaria.

\section{Requisitos de la gobernabilidad mu-} tualista. La ética es un elemento fundamental en el buen gobierno de las empresas de economía solidaria. Es un tipo de saber de los que pretenden orientar la acción humana en un sentido racional, que se expresa de manera concreta en dos formas: (i) aprender a tomar decisiones prudentes, (ii) aprender a tomar decisiones moralmente justas, donde la ética y la moral se encuentran identificadas.

Una condición indispensable para lograr un buen gobierno en las empresas de eco- 
nomía solidaria es tener un liderazgo ético, por esta razón es necesario desarrollar y promover las competencias, habilidades $\mathrm{y}$ aptitudes básicas para contar con un liderazgo más participativo.

En conclusión, el Sistema de Buen Gobierno (y su instrumento principal, el Código de Buen Gobierno) se entiende como la "manera como son dirigidas las entidades, mejorando su funcionamiento interna y externamente, en la búsqueda de eficiencia, integridad y transparencia, para responder adecuadamente ante sus grupos de interés, asegurando un comportamiento ético organizacional integral" (USAID, 2006).

Para que la gobernabilidad sea exitosa debe haber una unión entre el plan y la ejecución, entre la idea del desarrollo de la mutual y la satisfacción de las necesidades de los asociados; debe haber también unidad entre el poder político institucional (asamblea, junta directiva y comités) y el poder administrativo o cuadros gerenciales; debe haber afinidad entre los órganos de dirección y administración con la revisoría fiscal y /o con los auditores. Se debe lograr una cultura empresarial y que los asociados de la mutual sientan orgullo de pertenecer a ella, es decir, que sean militantes de la empresa mutual; esa cultura deberá ser retransmitida a las comunidades (entorno) donde se inserte cada una de estas empresas.

\section{Conclusiones}

1. El buen gobierno no sólo son apariencias externas, formalidades, procedimientos e intenciones, es también voluntad para llevar a la práctica la filosofía que inspiran las reglas y la conducta empresarial.

2. La práctica de los valores y principios se convierte en la máxima expresión del gobierno en las empresas mutuales.

3. Las empresas mutuales deben utilizar sus recursos de manera eficaz y estimular la relación con los asociados sobre la base de la confianza y de la transparencia de sus actividades.

4. Más allá de los transparentes beneficios económicos que persigue, se debe lograr generar bienestar en la organización y en el entorno en el que actúa.

5. La gobernabilidad en las empresas mutuales debe tomar en cuenta el desarrollo de un liderazgo ético basado en virtudes morales acordes con los principios del movimiento de economía solidaria.

6. La gestión de las empresas mutuales debe ser ante todo democrática, lo cual permite establecer los límites entre el ejercicio del poder y el control del mismo en el seno de la empresa mutualista. 


\section{Modelos propuestos y adaptados}

Se propone un sistema de gestión articulado en dos grandes bloques: gobierno de empresa y relación con las partes interesadas, de acuerdo con el modelo de FORETICA (Ogalla, 2006).
El sistema de gestión es la herramienta que permite controlar los efectos económicos y no económicos de la actividad de la empresa (Ogalla, 2005).

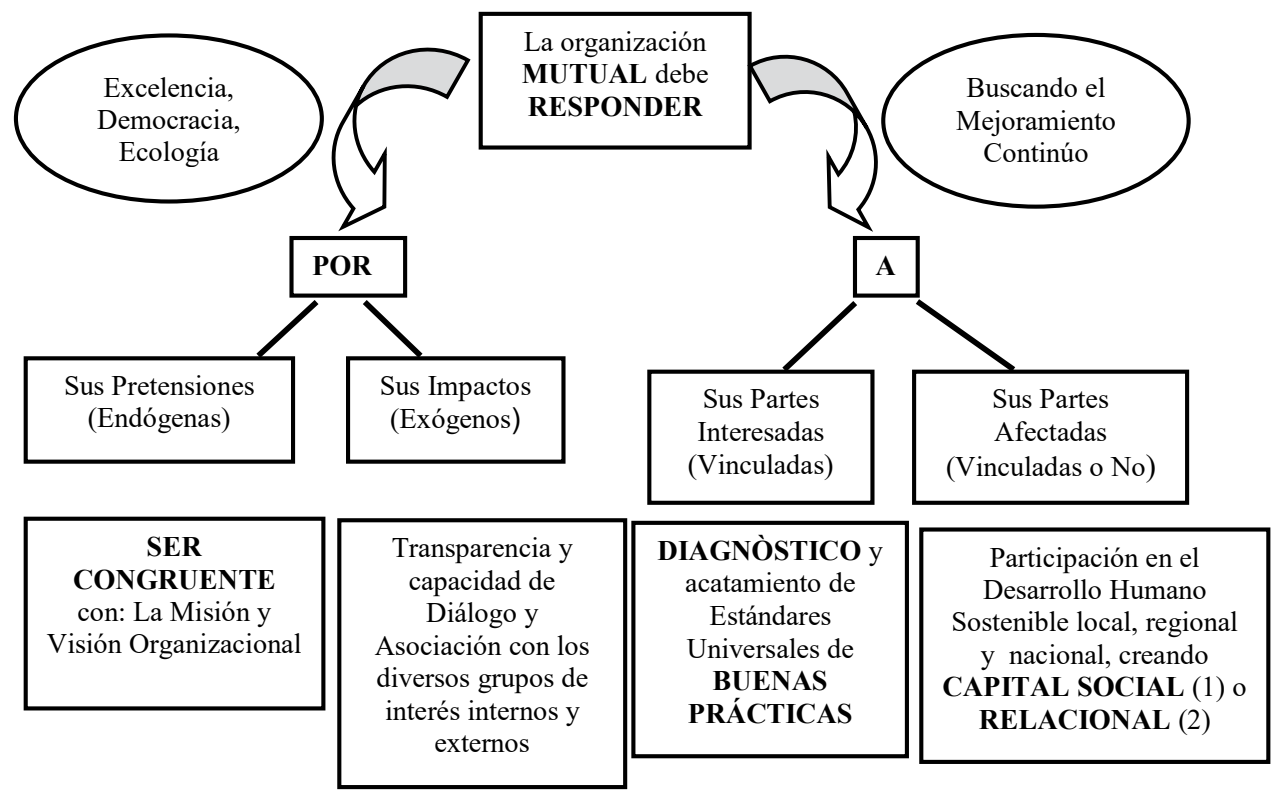

Figura 1. Sistema de Gestión Fuente: Ogalla (2005)

1: Variable que mide la colaboración social entre los diferentes grupos de un colectivo humano $\mathrm{y}$ el uso individual de las oportunidades surgidas a partir de ello, a partir de tres fuentes principales: la confianza mutua, las normas efectivas y las redes sociales.
2: Valor que tiene para la empresa mutual el conjunto de relaciones que mantiene con el exterior. La calidad y sostenibilidad de la base de asociados y su potencialidad para generar nuevos asociados y la relación con otros agentes del entorno de influencia. 


\section{Referencias}

Arzbach, M. (2004). Gobierno corporativo en mercados emergentes y el caso de las cooperativas de ahorro y crédito en América Latina. São Paulo, Brasil: DGRV.

Birchall, J. (2005). Los principios cooperativos diez años después. Revista de la Cooperación Internacional, 38(2).

Charkham, J. (1994). Keeping good company: A study of corporate governance in five countries. Oxford: Oxford University Press.

Colombo, P. (2003). Gobierno, Léxico de político-1. (H. Cardoso, Trad.) Buenos Aires: Nueva Visión.

Comisión Olivencia. (1998). Código de Buen Gobierno. El gobierno de las sociedades cotizadas. CNMV.

Cortina, A. (1994). Ética de la empresa, claves para una nueva cultura empresarial. Madrid: Trotta.

Cortina, A. (2002). Educación en valores y responsabilidad cívica. Primera Edición. Bogotá, D.C.: El Búho.

Gedajlovic, E. Y. (1998). Management and ownership effects: evidence from five countries. Strategic Management Journal, 533-555.
González, E. (1995). Manual sobre participación y organización para la gestión local (Foro Nacional por Colombia ed.). Bogotá.

Guédez, V. (2008). Ser confiable. Responsabilidad social y reputación empresarial. Venezuela: Planeta Venezolana S.A.

Kliksberg, B. (2008). Más ética, más desarrollo. (15ava ed.). San José, Costa Rica.

Lambert, P. (1959). La Doctrina Cooperativa. Buenos Aires, Argentina: Intercoop.

Lefort, F. (Agosto de 2003). Gobierno Corporativo: ¿Qué es? y ¿Cómo andamos por casa? En Cuadernos de Economía, 40(120): 207-237.

OCDE (Ed.). (1999). Principios de la OCDE para el gobierno de las sociedades. $\mathrm{Pa}$ rís: Organización para la Cooperación y el Desarrollo Económico.

Ogalla, S. (2005). Sistema de gestión. Una guía práctica. España: Diaz de Santos.

Ogalla, S. (2006). La integración de la responsabilidad social en el sistema de gestión de la empresa. Madrid, España: Foretica. 
Pérez Villa, P. E. (Julio - agosto de 2007). Participación democrática en las cooperativas. UNINOTAS.

Pérez Villa, P. E. y Múnera Vásquez, F. N. (2007). Reflexiones para implementar un sistema de gestión de la calidad (ISO 9001:2000) en cooperativas y empresas de economía solidaria. (Documento de trabajo). (Primera ed.). Bogotá, Colombia: Teoría del Color.

Razeto Migliaro, L. (1993). Los caminos de la economía de la solidaridad. Santiago de Chile, Chile: Ediciones Vivarium.

Reyno, M. M. (2006). Responsabilidad Social Empresarial (RSE) como ventaja competitiva. Universidad Técnica Federico Santa María. Departamento de Industrias. MBA.

Santonja, A. (2005). Teoría y práctica del bueno gobierno corporativo. Madrid, España: Marcial Pons.
Sen, A. (2001). Sobre ética y economía (Primera ed.). Madrid, España: Alianza Editorial Ensayo.

Suescún, V. y Zabala, H. (2010). La nueva agenda del mutualismo colombiano. (FEDEMUTUALES, Ed.) Medellín, Colombia: CTA de impresores de Artes Graficas de Antioquia.

Unidad de Estudios Solidarios UNES. (2005). Primer Congreso Nacional de Investigación del Sector Solidario. Memorias. Bogotá, Colombia: Pontificia Universidad Javeriana.

USAID. (2006). Modelo de gestión ética para entidades del Estado. Fundamentos conceptuales y manual metodológico. Recuperado de: http://transparenciabogota.gov.co/?wpfb_dl=101.

XV Congreso Nacional de Ética de la Economía y de las Organizaciones. (2007). El Buen Gobierno de las Organizaciones,IESE Business School. Barcelona. 